\title{
Maternal Healthcare Services and its Effect on child Health in India
}

\author{
Gulnawaz Usmani \\ Research Scholar, Department of Economics, Aligarh Muslim University, Aligarh, 202002, India
}

\begin{abstract}
Good maternal health is very crucial for country's health status. Today, India is growing well in every field. The health condition has improved over the years, maternal mortality and child mortality rates are declining drastically. But still the situation is worse when we compared with some developing and developed countries. Child health plays a vital role in the growth and development of a country. Maternal healthcare services have not implemented effectively, thus pregnant women and their children did not get adequate healthcare. The paper analyzes the effect of maternal healthcare services in the country and its effect on child health.
\end{abstract}

Keywords: Maternal health; Maternal health indicators; Child health; Child health indicators Child mortality indicators; India

\section{Introduction}

Today Indian economy counted among the best economies in the world. By the end of the decade, all the sectors of the economy show good performance, and the economy growing with a sound growth rate. Country goes well in all the areas of the development, such as agriculture, industry, and services. Per capita income and consumption in the country increased with the national income. Standard of living of the masses also goes up with increased employment opportunities and education level. But these improvements are not transformed into good health status in the country, although health sector shows very good performance in improving life expectancy at birth, nutritional status, maternal and child health etc. life expectancy at birth is almost more than double, health conditions of the population have improved, and a sharp decline in maternal and child mortality rates, and nutrition level has increased. Together with these improvements in maternal and child health care, the numbers of maternal mortality and child mortality is still very high, as compared to developed countries and some developing countries. In some states the number of maternal and child mortality are comparable to those of Sub-Saharan Africa and some other world's poorest countries.

According to the World Health Organization (WHO) maternal mortality is unacceptably very high around the world. Almost 830 women died every day from pregnancy and child birth related causes in the world which is equivalent to 33 an hour. According to the WHO reports, despite the improvement in the last two decades, there has been a little progress in preventing maternal mortality and its influences. Reports also show significant gaps in the availability in the availability, access and quality of healthcare services for women especially in the low income countries. India accounted almost a quarter of maternal deaths in the world, with a share of $17 \%$ of all the maternal deaths worldwide.

Improving maternal health condition is one of the eight MDGs (Millennium Development Goals). In 2000, countries committed to reduce the maternal mortality rates by three quarter up to 2015, and since then maternal mortality rates dropped gradually by 43 percent. Table 1 shows, India with a population of over a billion and a decadal growth of 17.64 percent, has its maternal mortality ratio at 167 in 2011-13 (SRS, 2011). In such a situation maternal healthcare services are crucially important in the country, which is experiencing high maternal mortality and child mortality. According to the Rapid Survey on Children 2013-14, infant mortality rate in India was 40 per 1000 live births in 2013, and under five mortality was 49 in the same period. Geographical and social diversity across the Indian States is the main reason for this variation in MMR. Generally, the status of women in India is low in India, except in the few states of southern and eastern part of the country. Education level among women is not as much good as it has to be, it is only $65.64 \%$ (Census, 2011), and in lack of women empowerment, women are not allowed to take decisions including, to use the reproductive healthcare services. Thus a woman faces so many health problems, especially related to her pregnancy.

There is a great inter-state variation on utilization of maternal health care services in India. Good health is an important development indicator in its own right. It is therefore very important to ensure that all the pregnant women and their newborn receive adequate maternal and child healthcare. Thus the main objective of the paper is to study the effect of maternal healthcare services on child health. Illness brings suffering, and good health especially maternal health leads to longer and healthier lives of women which can affect the child health positively.

\section{Objective and Sources of Data:}

This paper has two objectives -

- To study the maternal healthcare service utilization.

- To study the effect of maternal healthcare services on child health; Infant Mortality Rate (IMR).

\section{Methodology and Data Source}

In the study we use secondary data from various published reports of government of India. NFHS reports, census 2011, National Health Profile (NHP) of India reports and Rapid Survey on Children (RSoC) 2013-14 is also used. To study the effect of maternal health services on child survival we use simple correlation coefficient method. Correlation coefficient is a statistical method which measures the

\section{Volume 5 Issue 2, February 2016}




\section{International Journal of Science and Research (IJSR) \\ ISSN (Online): 2319-7064}

Index Copernicus Value (2013): 6.14 | Impact Factor (2014): 5.611

dependence and correlation between two or more random variables.

Table 1: Demographic and Health Indicators of India

\begin{tabular}{|c|c|c|}
\hline Indicators & Year & India \\
\hline Population in Million & Census 2011 & 12101.9 \\
\hline Population Growth Rate & $1991-2011$ & 17.64 \\
\hline Birth rate & 2010 & 18 \\
\hline Death rate & 2010 & 7.2 \\
\hline Total Fertility Rate & 2010 & 2.5 \\
\hline Female Literacy Rate & Census 2011 & 65.46 \\
\hline Sex Ratio & 2011 & 940 \\
\hline LEB (Female) & 2010 & 67.7 \\
\hline IMR & 2013 & 40 \\
\hline U5MR & 2010 & 59 \\
\hline MMR & 2013 & 167 \\
\hline
\end{tabular}

Source: Sample Registration System, Bulletin 2011, Govt. of India.

\begin{abstract}
Maternal Health and Process Indicators
Maternal health has remained on the top priority of the family welfare programme in India since the $1^{\text {st }}$ and $2^{\text {nd }}$ five year plan. When the government of India integrated maternal health with family planning, as a part of the minimum needs programme initiated during the $5^{\text {th }}$ five year plan. Maternal health plays a very key role in the health status of a nation. As mothers are the forerunners to healthcare of communities. Maternal health has a direct relationship with her family health status especially, with her newborn heath. A newborn whose mother dies during childbirth rarely survives. Mothers are more likely than fathers to support their children healthcare needs, which can lead to a healthy nation with more productive labourforce. Worldwide in the developing countries, half of all the pregnant women received minimum recommended antenatal care (ANC) visit, thus the number of complications during pregnancy and childbirth is comparatively higher in the region.
\end{abstract}

Maternal health is an old issue, but for developing nation it is a $21^{\text {st }}$ century problem. Maternal health can be improved; as we have seen in developed countries the maternal mortality has been eliminated through easy access to healthcare services and facilities. Improved maternal health not only saves mothers life, but improves the health condition of entire community.

Institutional Deliveries and Assistance During Delivery From the standpoint of maternal health, it is crucially important that the place of delivery/childbirth is clean and safe. Institutional deliveries are the deliveries that happened in a healthcare centre by a skilled health professional. Majority of maternal deaths or complications during pregnancies are due to the lack of institutional deliveries or failure to get timely care for the complications at the time of delivery. Thus it is very essential that the delivery should be conducted in a healthcare centre under proper hygienic conditions with the assistance of a trained healthcare practitioner. At present the percentage of institutional deliveries is 76.6 percent (Rapid Survey on Children, 201314)

\section{Antenatal Care (ANC)}

Antenatal care (ANC) refers to the pregnancy related healthcare during the pregnancy of women by a health professional in a healthcare centre or at home. ANC can contribute significantly to reduce the complications during pregnancy and childbirth because of dual effect of ANCs. Besides providing effective medical healthcare to pregnant women, it includes valuable advice on the good diet containing iron and folic acid tablets. Despite the high emphasis on ANCs by the government, only 19.7 percent of pregnant women have full antenatal visit in India (Rapid Survey on Children, 2013-14).

\section{Tetanus Toxoid Injection}

Tetanus is an important cause of death among maternal deaths and infants deaths. Tetanus is caused by the infection of newborn. Tetanus is very common among the deliveries that take place in an unhygienic condition, with nonsterilised medical instruments for cutting the umbilical cord of newborn. Tetanus is preventable with two doses of tetanus toxoid injection. One month apart during the early stage of pregnancy, two doses of tetanus toxoid is given to the pregnant women which is nearly hundred percent effective in preventing tetanus among the mothers and the newborn.

\section{Postnatal Care (PNC)}

Postnatal care is the care received women after birthing. The 48 hours after the delivery is very sensitive for many bacterial and organism infection and critical for the newborn and maternal survival. Out of total 2.9 million newborn deaths in 2012 (WHO), almost half of them occurred within the 24 hours after birth. PNC the basic care for all newborn include curative and primitive healthcare; promote early and exclusive breastfeeding, keeping the newborn warm, providing safe and hygienic umbilical cord and counseling when to take newborn to the healthcare centre. Despite the effective support of the government and steps to control the maternal and newborn deaths within first 24 hours after birth only 39.3 percent of newborns and mothers received postnatal care after 48 hours of delivery (RSoc, 2013-14).

Table 2, shows the data related to maternal healthcare service utilization in India and in some major states. It is indicated from the table that there is a wide diversity in the Indian states on the utilization of healthcare services. The percentage of mothers who received full ANC during pregnancy is 19.7 in India; while among the states, Kerala has the highest percentage of births for which mothers received full ANC (53.6 percent), followed by Andhra Pradesh with 38.2 percent and Tamil Nadu with 35.2 percent of births with full ANC. The percentage of women receiving full ANC is low in Uttar Pradesh (2.7 percent) and Bihar (9.6 percent). The Postnatal care (PNC) has also the same pattern of utilization in India and her states. The percentage of mothers receiving PNC within 48 hours of delivery is 39.3 in India; while among the states Tamil Nadu has the highest percentage of PNC (94.7 percent), followed by Kerala (94 percent). The states, Andhra Pradesh, Karnataka, Madhya Pradesh, and Maharashtra have also received PNC for more than 60 percent of births within 48 hours of delivery. The percentage of mothers received Tetanus Toxoid (TT) in India is about 89.8; while among the states 


\section{International Journal of Science and Research (IJSR) ISSN (Online): 2319-7064 \\ Index Copernicus Value (2013): 6.14 | Impact Factor (2014): 5.611}

Andhra Pradesh has the highest percentage of TT (97.1 percent), followed by Tamil Nadu (96.4 percent), Punjab (95.3 percent), Orissa (95.8 percent), and Assam (90.2 percent). It is indicated by the data (table 2), that all the remaining states have also received Tetanus Toxoid Injection for more than 80 percent of births. The proportion of institutional deliveries in India is about 78.7 percent and 81.1percent births, which take place in a medical facility and assisted by health professionals. Table 2 shows the interstate variations in the proportion of institutional deliveries and in deliveries assisted by health professionals. Among the states, Kerala has the highest percentage of institutional deliveries (99.4 percent), followed by Tamil Nadu (99.3 percent), Maharashtra (90.3 percent), Karnataka (92 percent), and Andhra Pradesh (91.1 percent). The institutional deliveries assisted by health professional. The percentage of institutional deliveries is low in Uttar Pradesh (62.1 percent) and Bihar (65.3 percent). The pattern of variation in the percentage of institutional deliveries assisted by health professionals is similar to the variation in institutional deliveries in India and her states.

Table 2: Maternal health Services by States:

\begin{tabular}{|c|c|c|c|c|c|}
\hline States & Institutional Deliveries & Full ANC* & Deliveries $(\mathrm{HP})^{* *}$ & TT*** injection & PNC**** (48 Hrs of Delivery) \\
\hline AP & 91.1 & 38.2 & 93.3 & 97.1 & 77.9 \\
\hline ASM & 74.2 & 25.2 & 74.9 & 90.2 & 7 \\
\hline BR & 65.3 & 9.6 & 68.4 & 88.6 & 6.4 \\
\hline GUJ & 87.9 & 25.7 & 89.6 & 87.6 & 23.5 \\
\hline HAR & 76.4 & 9.7 & 78.6 & 85.1 & 75.6 \\
\hline KAR & 92 & 33.4 & 92.6 & 93.2 & 94 \\
\hline KER & 99.4 & 53.6 & 99.5 & 95.1 & 70.3 \\
\hline MP & 78.1 & 12.1 & 79 & 88.9 & 10.5 \\
\hline MAH & 90.3 & 24.4 & 93 & 99.9 & 15.6 \\
\hline ORS & 81.3 & 24.6 & 83.7 & 95.8 & 9.5 \\
\hline PUJ & 80.4 & 15.5 & 85.4 & 82.6 & 94.7 \\
\hline RAJ & 82.7 & 8.6 & 85.8 & 96.4 & 12.1 \\
\hline TN & 99.3 & 35.2 & 99.5 & 81.3 & 9.1 \\
\hline UP & 62.1 & 2.7 & 65.1 & 96 & 39.3 \\
\hline WB & 76.3 & 21.2 & 78.9 & 89.8 & \\
\hline INDIA & 78.7 & 19.7 & 81.1 & & \\
\hline
\end{tabular}

Source: Rapid Survey on Children (RSoC), 2013-14, Ministry of Women and Child Development, Government of India.

*Antenatal Care, **Health Personnel, ***Tetanus Toxoid, ****Postnatal Care

\section{Child Health and Process Indicators:}

Child health has its importance in the healthcare sector. Child health indicates the well being of a country's children. The health challenges Indian children faced is bigger than any other country. Almost a quarter of total newborn deaths occur in India. Today's children are the tomorrow's citizens, which is why it is important to take care and ensure a proper healthcare to the newborn. The early years of life, that is the first six years of life are the most crucial period in the life, when the foundation are laid for growth and development. The young one below three years of life is the most vulnerable to the disease, nutrition problem, which influence the health condition of child at micro level and the human resource development of the nation at the macro level.
India is among the nations where child mortality is very high especially; infant mortality. According to the Sample Registration Survey (SRS) Data although, the infant mortality gradually declining over the years, there are some states where the number of Infant Mortality Rate (IMR) is very high. According to the SRS statistical report, 2013 the Infant Mortality Rate (IMR) is 40 in India. The ratio of IMR varies widely among different ranging from 12 per 1,000 live births in Kerala to 54 in Assam, followed by Uttar Pradesh with 50 IMR per 1,000 live births. The Under Five Mortality Rate (U5MR) also follows the same pattern, in India the U5MR is 49.

Table 3: Child Health Indicators by States, (SRS), 2013

\begin{tabular}{|c|c|c|c|c|c|c|c|c|c|c|c|c|c|c|c|c|}
\hline States & AP & ASM & BR & GUJ & HAR & KAR & KER & MP & MAH & ORS & PUJ & RAJ & TN & UP & WB & INDIA \\
\hline NNM & 27 & 29 & 28 & 28 & 28 & 23 & 7 & 39 & 18 & 39 & 17 & 35 & 15 & 37 & 22 & $\mathbf{2 9}$ \\
\hline IMR & 39 & 54 & 42 & 36 & 41 & 31 & 12 & 54 & 24 & 51 & 26 & 47 & 21 & 50 & 31 & $\mathbf{4 0}$ \\
\hline U5MR & 41 & 73 & 54 & 45 & 45 & 35 & 12 & 69 & 26 & 66 & 31 & 57 & 23 & 64 & 35 & $\mathbf{4 9}$ \\
\hline
\end{tabular}

Source: Sample Registration System (SRS), Statistical Report (2013).

\section{Neonatal Mortality (NNM)}

Neo-natal deaths refer to the deaths of newborn before completing 29 days of life. In 2010, the percentage of neonatal deaths to total infant deaths is 69.3 percent. The neonatal mortality rate in 2010 is 33 at national level which is declined to 29 in 2013, and ranges from 7 in Kerala as the lowest NNM followed by Tamil Nadu (15). The neo-natal is highest in Madhya Pradesh (39) and Orissa (39) (Table 2).

\section{Infant Mortality Rate (IMR)-}

Infant mortality Refers to the deaths of newborn before 365 days of life per thousand live births. In 2010, IMR is 47 in India which declined to 40 in 2013. The states of Kerala (12), Tamil Nadu (21) have the lowest infant mortality rate (IMR). The states of Assam (54), Madhya Pradesh (54), Bihar (42), Orissa (51), and Uttar Pradesh (50) have the IMR above the national level (40) (Table 2). 


\section{International Journal of Science and Research (IJSR) \\ ISSN (Online): 2319-7064 \\ Index Copernicus Value (2013): 6.14 | Impact Factor (2014): 5.611}

Under Five Mortality Rate (U5MR)-

The probability of a child born in a given year dying per thousand live births before reaching the age of five. According to the Sample Registration Survey (SRS), in 2010, the U5MR is 59 per thousand live births in India. Within a span of three years, U5MR has declined to 49 in
2013 (SRS, 2013). As in the case of IMR, Kerala has the lowest IMR (12), for U5MR also the lowest number of U5MR is in the Kerala (12). The states of Assam (73), Bihar (54), Orissa (66) and Uttar Pradesh (64) have the under five mortality rate above the national level (49) (Table 2).

Table 4: Correlation coefficient matrix of maternal and child health indicator:

\begin{tabular}{|r|r|r|r|r|r|r|r|r|}
\hline & \multicolumn{1}{|c|}{ ID } & \multicolumn{1}{c|}{ 3FANC } & \multicolumn{1}{c|}{ DHF } & \multicolumn{1}{c|}{ TT } & PNC & NNM & IMR & U5MR \\
\hline ID & 1 & & & & & & & \\
\hline 3FANC & 0.835005 & 1 & & & & & & \\
\hline DHF & 0.993832 & 0.804725 & 1 & & & & & \\
\hline TT & 0.562817 & 0.72018 & 0.568726 & 1 & & & & \\
\hline PNC & 0.838746 & 0.739338 & 0.809276 & 0.414251 & 1 & & & \\
\hline NNM & -0.62878 & -0.66786 & -0.63982 & -0.53441 & -0.5574 & 1 & & \\
\hline IMR & -0.69542 & -0.64047 & -0.71803 & -0.50982 & -0.6241 & 0.951444 & 1 & \\
\hline U5MR & -0.71119 & -0.62675 & -0.73752 & -0.5016 & -0.64589 & 0.924997 & 0.987473 & 1 \\
\hline
\end{tabular}

ID - Institutional Deliveries 3FANC - Three Full ANC

DHF - Delivery by Health Professional TT - Tetanus Toxoid

PNC - Postnatal Care

\section{Results}

Table 4 shows the coefficient correlation between maternal and child healthcare variables. Almost all of the maternal healthcare indicators have a high negative correlation with child mortality indicators. The negative sign before the correlation value indicates the inverse relationship. That is, the better the maternal healthcare services, the child mortality (IMR, U5MR, NNM) will be improved, or the influence of maternal healthcare services is in reverse direction. The correlation between ANC and neo-natal mortality is -0.66 , between ANC and infant mortality is 0.64 , with under five mortality it is -062 . The correlation between institutional deliveries and neonatal mortality is 0.62 , with infant mortality it is -0.69 , with under five mortality it is -0.71 . Correlation coefficient between infant mortality rate and other maternal healthcare indicator have also a strong negative correlation. The correlation between IMR and deliveries by health professionals is -0.71 , with tetanus toxoid it is -050 , with postnatal care within 48 hours of delivery it is -0.62 . From table 4 , it is noted that the women delivered in a medical institution by health professionals and received 3 full antenatal care have comparatively high correlation with infant mortality and others measures of child mortality. Again it is noticed from the table 4 , that there is a significant correlation between infant deaths and maternal healthcare indicators, but the values of correlation are lower as compared to infant mortality and under five mortality rate. This indicates that there is need for some more effective maternal healthcare programmes, because neonatal mortality is mainly affected by the biological factors. Government should take some more fruitful steps to increase the institutional deliveries by health professionals.
Table 5: Affect of Poverty on MMR and IMR:

\begin{tabular}{|c|c|c|c|c|}
\hline States & $\begin{array}{c}\text { No. of persons } \\
\text { (lakh) }\end{array}$ & $\begin{array}{c}\text { \% of BPL Population } \\
\text { (Tendulkar } \\
\text { Methodology) }\end{array}$ & MMR & IMR \\
\hline AP & 78.78 & 9.2 & 92 & 39 \\
\hline ASM & 101.27 & 31.98 & 300 & 54 \\
\hline BR & 358.15 & 33.74 & 208 & 42 \\
\hline GUJ & 102.23 & 16.63 & 112 & 36 \\
\hline HAR & 28.83 & 11.16 & 127 & 41 \\
\hline KAR & 129.76 & 20.91 & 133 & 31 \\
\hline KER & 23.95 & 7.05 & 61 & 12 \\
\hline MP & 234.06 & 31.65 & 221 & 54 \\
\hline MAH & 197.92 & 17.35 & 68 & 24 \\
\hline ORS & 138.53 & 32.59 & 222 & 51 \\
\hline PUJ & 23.18 & 8.26 & 141 & 26 \\
\hline RAJ & 102.92 & 14.71 & 244 & 47 \\
\hline TN & 82.63 & 11.28 & 79 & 21 \\
\hline UP & 11.6 & 11.26 & 285 & 50 \\
\hline WB & 184.98 & 19.98 & 113 & 31 \\
\hline INDIA & 2697.83 & 21.92 & 167 & 40 \\
\hline
\end{tabular}

Source: Census of India 2011, Registrar General of India. Sample Registration System (SRS) 2013, Govt. of India.

Effect of Female Literacy on Maternal and Child Health: Female education plays a vital role in her health status, and her family, especially to the child health. A well educated mother takes care of her baby, better than an uneducated mother. Education plays a significant role in improving health status. Education makes people more aware about the health issues. A literate woman is more aware about the maternal and child health care services running in the country, so she can use them more efficiently than an unaware woman. Literacy level makes her empowered enough to take right decision regarding contraception, birth spacing, access to healthcare centres, and other health concern issues, that might affect the health of the mother as well as child. Table 6 shows the data on female literacy level and MMR, IMR in India and her states. 


\section{International Journal of Science and Research (IJSR) \\ ISSN (Online): 2319-7064}

Index Copernicus Value (2013): 6.14 | Impact Factor (2014): 5.611

Table 6: MMR and IMR according to Female Literacy in Indian States:

\begin{tabular}{|c|c|c|c|c|c|c|c|c|c|c|c|c|c|c|c|c|}
\hline States & AP & ASM & BR & GUJ & HAR & KAR & KER & MP & MAH & ORS & PUJ & RAJ & TN & UP & WB & INDIA \\
\hline LR (F) & 59.15 & 66.27 & 51.5 & 69.68 & 65.94 & 68.08 & 92.07 & 59.24 & 75.87 & 64.01 & 70.73 & 52.12 & 73.44 & 57.18 & 70.54 & 64.64 \\
\hline MMR & 92 & 300 & 208 & 112 & 127 & 133 & 61 & 221 & 68 & 222 & 141 & 244 & 79 & 285 & 113 & 167 \\
\hline IMR & 39 & 54 & 42 & 36 & 41 & 31 & 12 & 54 & 24 & 51 & 26 & 47 & 21 & 50 & 31 & 40 \\
\hline
\end{tabular}

Source: Sample Registration System (SRS), 2013

According to the SRS, 2013 data, female literacy level is 64.64 percent at the national level. The states of Kerala (62.07) and Maharashtra (75.87) have the highest female literacy level. The states of Rajasthan (52.12), Uttar Pradesh (57.18), and Bihar (51.5) are among the states of low female literacy level. The states with low level of female education level have the highest number of maternal and child mortality rate as compared to the states with high level of female education (Table 6).

Table 7: Correlation coefficient matrix of Maternal and Child Health Indictors with BPL families and female literacy level

\begin{tabular}{|c|c|c|c|c|}
\hline & Literacy Rates (F) & $\%$ BPL families & MMR & IMR \\
\hline Literacy Rates (F) & 1 & & & \\
\hline \% BPL families & -0.41 & 1 & & \\
\hline MMR & -0.67 & 0.55 & 1 & \\
\hline IMR & -0.80 & 0.61 & 0.86 & 1 \\
\hline
\end{tabular}

\section{Results}

Table 7, shows the coefficient correlation between BPL population and health indicators of maternal and child health. It is clear from the table that correlation coefficient between the poverty and maternal and child health indicators are significant, but the values are lower, when compared with the correlation value of maternal health indicator MMR and child health indicator. Table shows that the maternal and child health care indicator has a positive value with the poverty indicator. The positive sign indicates the influence in same direction. That is, lower the BPL population; lower the maternal mortality and infant mortality. The correlation between BPL population and MMR is 0.55 , with IMR it is 0.61. The correlation between MMR and IMR is comparatively higher with a positive value. Again it is evident from the table that there is a strong correlation between the maternal health and child health. The coefficient correlation between the maternal health indicator and child health indicator is 0.86 .

The correlation coefficient matrix (Table 7) shows that the women education has a high correlation with maternal mortality and infant mortality. The correlation between female literacy and MMR is -0.67 , with IMR it is -0.80 . Correlation coefficient between maternal health and child health is also seen in the table 7 . It is noted that the correlation between maternal mortality rate and infant mortality has a positive value. The correlation between MMR and IMR has a comparatively high value of 0.86 which indicate that maternal health has a direct effect on the child health. The association between female literacy rate and maternal mortality rate is significant, but the value of correlation is lower as compared to the value between female literacy level and infant mortality rate. Thus it is evident from the table 8, that female literacy level has also affected the child health condition. Government should try to increase the education level among women through some effective measures.

Figure below show the bar graph of female literacy level and Maternal and Child mortality indicator. The red bar shows the MMR level, while the blue bar for literacy level and green bar is for IMR. 


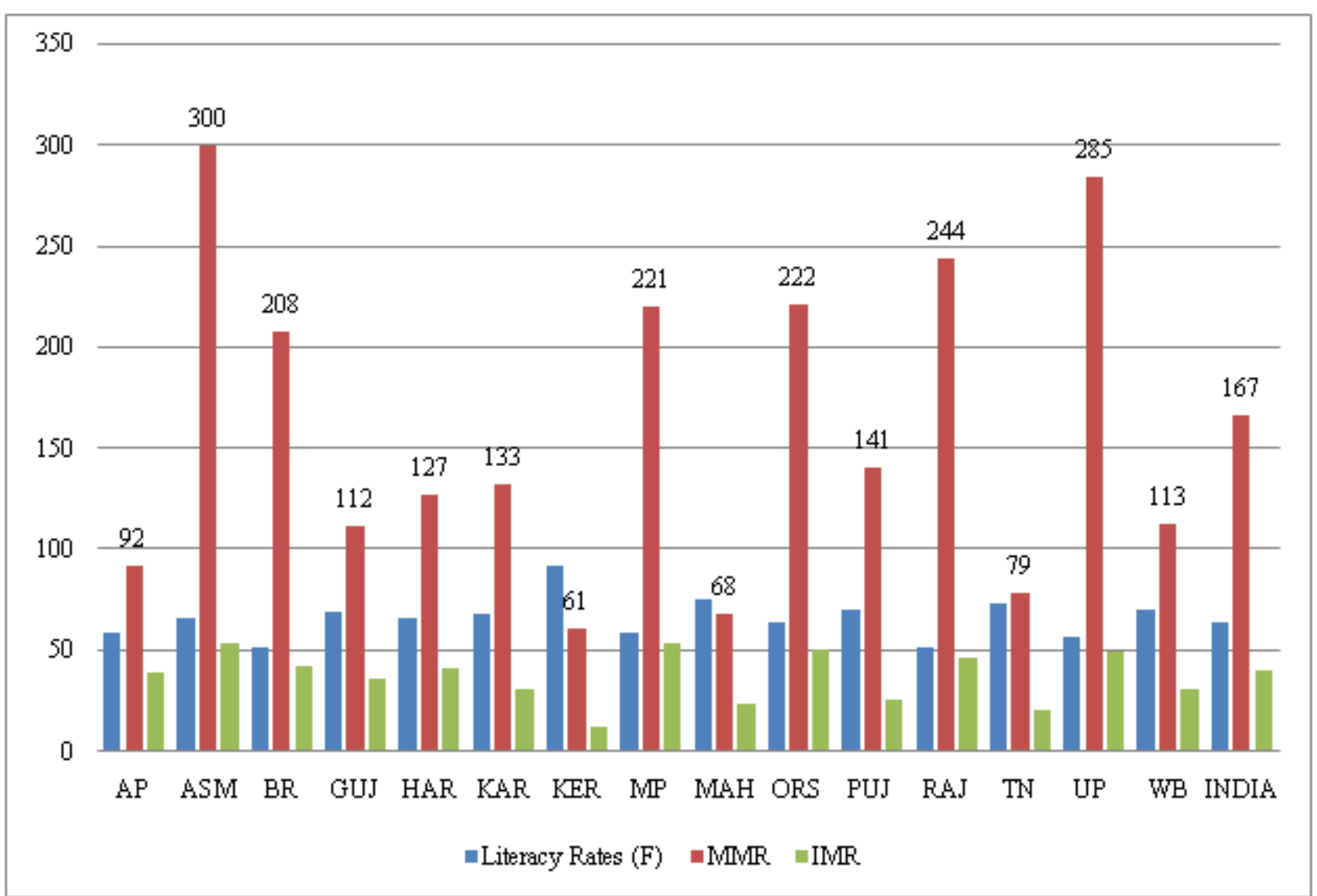

Figure: Female Literacy level and Maternal and Child Health

Source: Sample Registration System (SRS), 2013, Govt. of India

\section{Conclusion}

This paper made an attempt to study the affect of maternal healthcare services on child health in India. The data for the analysis were taken from Census Reports (2011), and Rapid Survey on Children (RSoC) 2013-14. The maternal healthcare services considered for the analysis are antenatal care, tetanus toxoid injection, institutional deliveries, and deliveries by health personnel's.

The child health indicators considered for the analysis are infant mortality rate (IMR), neonatal mortality rate (NNM), and under five mortality rate (U5MR). Child health indicators vary dramatically between the states. The IMR varies from 12 in Kerala to 54 in Assam. The IMR for India is 40 . Likewise, there is a significant difference between the states on each of the indicator maternal healthcare service utilization and child health. The variation in the mothers who received antenatal care is similar to the variation in the percentage of receiving tetanus toxoid injection. Again, the variations in the birth delivered in medical facilities between the states are similar to the variation in the delivery by health professionals. For the safety of the health of child and mother, the first priority for delivery is that it must be by health personnel and it should be clean, hygienic and safe. Inadequate healthcare during the birth enhance the risk both to the child and mother.

All maternal healthcare services were highly correlated with different child mortality indicators. The value of correlation on neo-natal mortality (NNM) is low, which indicate that the neonatal deaths are mostly biological in nature (Table 4).
The value of correlation of female literacy level with IMR and MMR is similar to the value of correlation between BPL families and IMR and MMR. Though the correlation between female literacy level and MMR is low but the value is significant. Even though all the maternal healthcare services have some influence on the child health the analysis shows that there is need for further implementation of maternal healthcare services.

The above findings create a space for developing a strong programme with respect to maternal health and child health. There are various causes of the high IMR, NNM, U5MR, and MMR such as, low birth weight, unsafe delivery, neonatal tetanus, and high fertility rate. Hence there is a need to promote maternal healthcare services which will accelerate the declining of the rate of the child mortality indicators.

\section{References}

[1] Census of India 2011, Office of the Registrar General of India, New Delhi.

[2] Sample Registration Survey (SRS), Statistical Report, 2013, Office of the Registrar General of India, New Delhi.

[3] Rapid Survey on Children (RSoC), 2013-14, Ministry of Women and Child Development, Government of India.

[4] National Family Health Survey Reports, Indian Institute of Population Science, Mumbai. 


\section{International Journal of Science and Research (IJSR) \\ ISSN (Online): 2319-7064}

Index Copernicus Value (2013): 6.14 | Impact Factor (2014): 5.611

[5] Millennium Development Goals, India Country Report 2015, Social Statistics Division, Ministry of Statistics and Programme Implementation, Government of India,

[6] India. Ministry of health and Family Welfare. National health policy 2002. (http://mohfw.nic.in/np2002.htm, accessed on 19 September 2003).

[7] Health information of India-2005. Chapter 7. Manpower statistics.

[8] Shiffman J, Ved RR. The state of political priority for safe motherhood in India. $\mathrm{Br} \mathrm{J}$ Obstet Gynaecol 2007;114:785-90.

[9] 7

-------------------------Implementation completion report: India. Child Survival and Safe Motherhood Project. Washington, DC: World Bank, 1997.

[10] National family health survey (MCH and family planning), International Institute for Population Sciences, India, 1992-93. Mumbai. 